\title{
Corona Virus Disease-19 pandemic: The gastroenterologists' perspective
}

\author{
Jahnvi Dhar ${ }^{1}$ Jayanta Samanta ${ }^{1}$ (D) $\cdot$ Rakesh Kochhar $^{1}$
}

Received: 21 May 2020 / Accepted: 8 July 2020 / Published online: 12 August 2020

(C) Indian Society of Gastroenterology 2020

\begin{abstract}
The world is witnessing a serious public health threat in the wake of the third corona virus pandemic, a novel corona virus (severe acute respiratory syndrome coronavirus 2 [SARS-CoV-2]). The Corona Virus Disease-19 (COVID-19) is not limited to the respiratory system but has widespread involvement including the gastrointestinal (GI) tract and liver, with evidence of prolonged fecal shedding and feco-oral transmission. This finding has stirred up a hornet's nest of not only a newer modality of the spread of the virus but also a risk of the unpredictable duration of the infective potential of the shedders. We reviewed the literature on fecal shedding and possible implications on prevention and surveillance strategies. The pandemic is changing the management of underlying chronic diseases such as inflammatory bowel disease (IBD) and other diseases. Moreover, for the gastroenterologist, doing endoscopic procedures in this COVID-19 era poses a high risk of contamination, as it is an aerosol-generating procedure. There is a daily influx of data on this disease, and multiple societies are coming up with various recommendations. We provide a comprehensive review of all the reported GI manifestations of COVID-19 infection and the side effects of confounding drugs. We have summarized the management recommendations for diseases such as IBD with COVID-19 and nutritional recommendations and provided a concise review of the endoscopy guidelines by the various societies. This review provides a comprehensive account and a lucid guide covering various aspects of gastroenterology practice during this COVID-19 pandemic.
\end{abstract}

Keywords Colon · COVID-19 · Endoscopy · Fecal · Gastrointestinal · Inflammatory bowel disease $\cdot$ Novel coronavirus · Pandemic $\cdot$ Severe acute respiratory syndrome $\cdot$ Viral pneumonia

\section{Introduction}

Severe acute respiratory syndrome coronavirus 2 (SARSCoV-2), a novel coronavirus, was first detected in the Wuhan City of China in December 2019. Since then, it has spread in the last 5 months to become a worldwide pandemic. Even as we write this article, the virus has already affected more than 6 million people and claimed 300,000 lives [1].

Jahnvi Dhar and Jayanta Samanta are authors that have contributed equally to the work and considered as joint first authors

Electronic supplementary material The online version of this article (https://doi.org/10.1007/s12664-020-01075-2) contains supplementary material, which is available to authorized users.

Jayanta Samanta

dj_samanta@yahoo.co.in

1 Department of Gastroenterology, Post Graduate Institute of Medical Education and Research, Chandigarh, Sector - 12, Chandigarh 160 012, India
India has already reported more than 200,000 cases and 6000 deaths. While the virus was initially thought to be a respiratory pathogen, the extra-pulmonary effects of the virus and the mode of transmission gained limelight when the first diagnosed case of Corona Virus Disease-19 (COVID-19) from the USA had gastrointestinal (GI) complaints [2]. Since then, more and more studies have looked into the effects of COVID-19 on the GI tract and liver with increasing reports of higher frequency than initially reported. We provide a concise review of the relevant published articles and have summarized the overall incidence rates reported to date for the various GI manifestations. The liver manifestations are beyond the scope of this article. The possibility of feco-oral transmission has been suggested with fecal sample positivity for SARS-CoV-2 strain. This not only highlights a newer modality of the spread of the virus but also makes it difficult to assess the duration for which a viral shedder is infective. Thus, it has important implications for the prevention and surveillance strategies that need to be adopted. COVID-19 can also adversely affect the already existing GI diseases, 
and hence, the optimum management strategies need to be reviewed. Various endoscopic societies have clearly highlighted the increased risk of endoscopic procedures during this pandemic and thus the need for extra precautions for the practicing gastroenterologists. Thus, in this review, we give a comprehensive overview of various aspects of COVID-19 for the practicing gastroenterologist in a userfriendly way for daily practice and the precautions to be taken.

\section{Information sources and literature search}

A review of literature was carried out through PubMed, Medline, and Google Scholar search engine for all relevant English-language articles/abstracts using a search query constructed with the following medical subject heading (MeSH) terms: "severe acute respiratory syndrome coronavirus 2" OR "COVID-19" OR "coronavirus 2019" OR "SARS-CoV2") AND ("Gastroenterology" OR "Gastrointestinal" OR "signs and symptoms, digestive" OR "GI" OR "diarrhea" OR "gastr*" OR "Inflammatory bowel disease" OR "IBD" OR "endoscopy" OR "Colon*" OR "fecal" OR "Stool"). The reference list of the papers, webpages of major gastroenterology and hepatology journals, and websites of the World Health Organization (WHO) and Center for Disease Control (CDC) publications were reviewed and all relevant data extracted. Additional published and unpublished studies from other platforms such as medRxiv and Social Science Research Network (SSRN) were also searched. For the recommendations, all the latest guidelines of the major gastrointestinal and endoscopy societies were reviewed (including online suggestions and pre-proof) by the authors and all framed into a narrative review.

\section{Corona virus pathogen}

SARS-CoV-2 is a zoonotic, single-stranded, positive-sense, enveloped, ribonucleic acid (RNA) beta-coronavirus. This family also includes the severe acute respiratory syndrome-related coronavirus (SARS-CoV) and Middle East respiratory syndromerelated coronavirus (MERS-CoV), which bear a phylogenetic similarity of $79 \%$ and $50 \%$, respectively with SARS-CoV-2 strain [3]. Electron micrograph images reveal its diameter to be 60-140 $\mathrm{nm}$ and the appearance of a solar corona (crown-like) due to the presence of spikes (diameter 9-12 nm).

The world has already witnessed the pandemics of former 2 strains, in 2002-2003 (SARS) and in 2012 (MERS). The third coronavirus pandemic started as pneumonia of unknown etiology, which was designated as SARS-CoV-2 by the International Committee on Taxonomy of Viruses and later rechristened as COVID-19 by the WHO [4].

The virus has been thought to have a zoonotic origin, due to phylogenetic similarity to horseshoe bats. It has an easy person-to-person transmission, even in the asymptomatic phase of the disease. Furthermore, community transmission of the virus has been proven across all affected continents.

A large epidemiological study from China of 72,314 cases showed an overall case fatality rate of $2.3 \%$, with $3.8 \%$ affected being health care workers (HCWs) [5]. A recent metaanalysis estimated mortality at $2.0 \%$ to $4.4 \%$ [6]. COVID-19 has already exceeded the morbidity and mortality of the previous coronavirus outbreaks (SARS, 774 deaths in 20022003, and MERS, 848 deaths in 2012) and at this rate, it might be as catastrophic as the Spanish flu of 1918 [7, 8].

\section{Classical symptoms}

The 3 main members of the coronavirus family (SARS-CoV, MERS-CoV, and SARS-CoV-2) are categorized mainly as respiratory pathogens following a principle of human-tohuman transmission by droplet, aerosols, and contact route. The main symptomatology of COVID-19 pertains to respiratory system with patients presenting predominantly with fever, cough, sore throat, and shortness of breath, and acute respiratory distress syndrome (ARDS) in patients with severe disease [4].

The pathogenesis encompasses attachment of the virus to angiotensin-converting enzyme type 2 (ACE2) receptor on the lung type 2 alveolar cells (AT2). Once the spike protein (S) attaches to the alveolar cells, it leads to a cytokine storm leading to alveolar flooding and denudation of the lining epithelium, hampering oxygen exchange and manifesting clinically as ARDS [9].

In the first study from Wuhan, China, out of 41 cases, 27 (66\%) had positive contact history. Common symptoms were fever $(98 \%)$, cough $(76 \%)$, shortness of breath $(55 \%)$, and fatigue (44\%), and $28 \%$ had sputum production and only one case had diarrhea [4]. Hence, most of the studies published initially discussed primarily the respiratory complaints and the diagnosis was based on testing of oro-pharyngeal swabs by reverse transcriptase-polymerase chain reaction (RT-PCR) for SARS-CoV-2. Eventually, GI symptoms gained precedence and more and more reports hinted at a larger proportion of patients having GI involvement.

\section{GI manifestations: pathogenesis and reported literature}

The first confirmed case detected in the USA had presented with cough, nausea, and vomiting followed 2 days later by diarrhea and the fecal specimen was positive on the 7th day [2]. This led to heightened attention towards GI tract being a potential route of virus spread. Previous studies had revealed that $10.6 \%$ of SARS and $30 \%$ of MERS cases had diarrhea 
[10]. In the early stage of the pandemic, only $3 \%$ to $3.8 \%$ cases of diarrhea and 5\% cases of nausea and/or vomiting were reported $[4,11]$, but later studies cited as high as $79 \%$ of cases having digestive symptoms [12]. In fact, studies reported from countries outside China reported a higher prevalence of GI symptoms as compared with those from China [12]. Still more fascinating are the cases presenting with only GI involvement without respiratory findings.

The various GI manifestations reported currently include diarrhea, loss of appetite, nausea, vomiting, and/or pain in the abdomen. Loss of taste and smell and even GI bleeding either at the time of admission or during the hospital stay have also been reported. A summary of the various GI manifestations have been outlined in Appendix Panel 1.

\section{Pathophysiology}

The multisystem involvement of the virus, including the GI tract, can be explained by looking at its pathophysiology. The entry of the SARS-CoV-2 is mediated by the interaction of the viral spike protein and the host ACE2 cell receptor (a regulator of intestinal inflammation), which combines with host cellular trans-membrane serine protease 2 (TMPRSS2) [13]. SARS$\mathrm{CoV}-2$ has greater efficiency to bind to receptor S protein, responsible for virus invasion [14]. ACE2 and TMPRSS2 were found not only in the lung AT2 cells but also in abundance in esophageal epithelial cells and absorptive enterocytes of the ileum and colon [15]. Liang et al. [16] demonstrated a high ACE2 expression in the proximal and distal enterocytes. Moreover, ACE2 is associated with neutral amino acid transporter, B0AT1, and has a role in the regulation of intestinal microflora [17]. Hence, the interaction of SARS-CoV-2 with ACE2 may lead to dysbiosis and inflammation. Endoscopy performed in cases with diarrhea showed evidence of virus expression in the esophagus, stomach, duodenum, and rectum, proving that the virus can flourish throughout the GI tract [18]. The glycosylation of S protein, the evolution of intrinsic resistance, or the formation of tight complexes with mucins could possibly explain the ability of the virus to sustain the adverse milieu of low $\mathrm{pH}$ of the stomach and the bile salts [19]. Thus, the augmented invasive property of the virus along with the abundance of its attaching receptors along the GI tract can explain its GI manifestations. To date, only a single autopsy report detailed the GI findings of an 85-year-old male patient with COVID-19, showing segmental dilation and stenosis of the small intestine [20]. Whether this finding is specific for COVID-19 is only speculative and more data is warranted.

The mechanisms postulated for diarrhea in SARS-CoV-2 infection are [13, 21-23] (i) direct virus entry through the ACE2 receptor (leading to malabsorption, unbalanced intestinal secretion, and activated enteric nervous system); (ii) direct/ indirect damage to the intestinal epithelium by an inflammatory response (probably related to cytokine storm; interleukin-6); (iii) antibiotic and/or antiviral drugs induced intestinal dysbiosis leading to diarrhea or exacerbation of the underlying condition; (iv) the virus itself causing disorders of the intestinal flora (which needs further evaluation by luminal flora and stool flora specimen analysis and comparison); and (v) the disturbance of the "gut-lung axis" wherein respiratory flora adversely affects the digestive system by immune regulation, a possible explanation for COVID-19 pneumonia cases having diarrhea.

\section{Reported literature}

In a systematic review published by Tian et al. [24], anorexia was the most common symptom in adults (39.9\% to 50.2\%), followed by diarrhea (both in adults and children) (2\% to $49.5 \%$ ) while vomiting was more common in children $(6.5 \%$ to $66.7 \%$ ) and abdominal pain more predominant in sick patients. Anorexia, though much more commonly reported than other digestive symptoms, is difficult to assess objectively. Hence, the most common definitive GI symptom would be diarrhea ( $1 \%$ to $36 \%)$ [25].

Diarrhea might be the first indication of an underlying SARS-CoV-2 infection. COVID-19 presenting as diarrhea at onset was first reported in a patient from China [26] and later reported from other countries as well [27, 28]. Fang et al. [29] reported $22.2 \%$ of cases presenting with diarrhea before the clinical diagnosis of COVID-19, while Wang et al. [30] reported 14 patients (of 138 cases) to have diarrhea and nausea 1-2 days before the onset of fever or dyspnoea. The pooled estimate of GI symptoms as presenting manifestations has been found to be $9.3 \%$ to $10 \%[12,31]$. It usually occurs around 1-8 days from the onset of symptoms and is usually self-limiting. The frequency has been reported to be $3.3 \pm 1.6 /$ day (range $2-10$ ) with a mean duration of $4.1 \pm 2.5$ days (range 1-14 days) [29]. Interestingly, patients who presented with GI symptoms had prolonged interval of symptom-onset to hospital admission [31].

Whether GI symptoms have any relationship with the severity of the disease is not fully established. A few studies have reported no significant difference in GI symptoms between severe and mild cases [11,29]. On the contrary, Wang et al. [30] reported more anorexia and abdominal pain in intensive care unit (ICU) patients (anorexia 66.7\% vs. $30.4 \%$; abdominal pain $8.3 \%$ vs. $0 \%$ ) while Jin et al. [32] showed higher GI manifestations in critical cases $(22.97 \%$ vs. $8.14 \%$ ). These and others raise the possibility of GI symptoms being associated with more severe disease [31]. A recent meta-analysis pointed out that hospitalized patients had a higher prevalence of diarrhea compared with the outpatients (10.4\% vs. $4 \%)$ [12]. Interestingly, pooled analysis reported abdominal pain to be associated with increased COVID-19 
severity, not the presence of diarrhea, loss of appetite, or nausea/vomiting [31, 33].

In a study of 74 cases of COVID-19 with GI symptoms, Jin et al. [32] highlighted that $28 \%$ had no respiratory symptoms. Similarly, Ping et al. [34] and Pan et al. [35] have reported 9 and 7 cases with GI complaints without respiratory symptoms, respectively. In a larger study by Luo et al. [36], 16\% (183 of 1141) of patients presented with only GI symptoms. This cohort had more of loss of appetite (15.8\%) and nausea/vomiting (11.7\%) and less of diarrhea (6\%) and abdominal pain (3.9\%). These cases emphasize that pure GI form of COVID-19 exists, though less common, and can confuse and confound the clinical scenario. This pure GI form poses a red flag sign for the gastroenterologists and warrants better selfprotection from unsuspected cases in this COVID-19 era.

Children have been reported to have milder COVID-19 infection with similar rates of diarrhea $(9.6 \%$ to $15 \%)$ but possible higher rates of vomiting $(6.5 \%$ to $66.7 \%)[24,31$, 37]. Supplementary Table 1 highlights all the relevant, selected studies in both children and adults, based on the manifestations of COVID-19 on the GI tract.

Disturbances in the olfactory and gustatory function have of late been reported to be associated with SARS-CoV-2 infection. Since the initial description of this finding by Mao et al. [38], multiple reports of new-onset olfactory and gustatory dysfunction in association with other COVID-19 have surfaced. A recent meta-analysis reported a prevalence of $43.9 \%$ for gustatory dysfunction and $36.6 \%$ (using non-validated instruments) to $86.6 \%$ (using validated instruments) for olfactory dysfunction [39]. Recently, CDC has added "new loss of taste or smell" to its list of symptoms for COVID-19, which may appear 2-14 days after the exposure [40].

A host of drugs have been tried for the COVID-19 treatment including antivirals, anti-malarial, and various monoclonal antibodies. While their efficacy is yet to be established, it is crucial that gastroenterologist be acquainted with the adverse effects of these medications on the GI tract and liver and not equate everything to direct manifestations of SARSCoV-2 infection [41] (Table 1).

Table 1 Drugs used in Corona Virus Disease-19 (COVID-19), dosing, and their gastrointestinal-/liver-related side effects

\begin{tabular}{|c|c|c|c|}
\hline COVID-19 treatments & Dose for COVID-19 infection & Dosing route & Gastrointestinal-/liver-related side effects \\
\hline Remdesivir & $\begin{array}{l}200 \mathrm{mg} \text { single dose followed } \\
\text { by } 100 \mathrm{mg} \text { OD for } 10 \text { days }\end{array}$ & Intravenous & $\begin{array}{l}\text { Nausea, vomiting, deranged } \\
\text { liver enzymes }\end{array}$ \\
\hline Hydroxychloroquine & $\begin{array}{l}\text { 1200/800 mg loading dose on } \\
\text { day } 1 \text { followed by } 400 \mathrm{mg} \\
\text { daily (prophylaxis: } 400 \mathrm{mg} \\
\text { once weekly for } 8 \text { weeks) }\end{array}$ & Oral & $\begin{array}{l}\text { Nausea, vomiting, weight loss, } \\
\text { abdominal pain }\end{array}$ \\
\hline Chloroquine & $500 \mathrm{mg} \mathrm{BD}$ & Oral & $\begin{array}{l}\text { Increased liver enzymes, anorexia, } \\
\text { nausea, vomiting, diarrhea, } \\
\text { abdominal cramps }\end{array}$ \\
\hline Azithromycin & $500 \mathrm{mg}$ OD & Oral & Diarrhea, nausea/vomiting, pain abdomen \\
\hline Tocilizumab & $\begin{array}{l}8 \mathrm{mg} / \mathrm{kg} \text { IV once (can combine } \\
\text { with steroids); max } 3 \text { doses }\end{array}$ & Intravenous & $\begin{array}{l}\text { Elevated liver enzymes, bowel perforation, } \\
\text { pancreatitis, abdominal pain, } \\
\text { reactivation of chronic hepatitis B }\end{array}$ \\
\hline Lopinavir/ritonavir & $400 \mathrm{mg} / 100 \mathrm{mg} \mathrm{BD}$ & Oral & $\begin{array}{l}\text { Nausea and vomiting }(5-10 \%) \text {; abdominal } \\
\text { pain }(1-10 \%) \text {; diarrhea }(10-30 \%) ; \\
\text { dysgeusia }(<2 \%) \text {; increased serum } \\
\text { amylase/lipase. Deranged liver } \\
\text { enzymes; in few cases, jaundice } \\
\text { reported in HIV-infected people }\end{array}$ \\
\hline Favipiravir & $\begin{array}{l}1000-1600 \mathrm{mg} \text { on the first day, } \\
\text { followed by } 400-800 \mathrm{mg} \mathrm{BD} \\
\text { for } 4-13 \text { days (being tried } \\
\text { in clinical trials) }\end{array}$ & Oral & Nausea/vomiting (5-15\%); diarrhea (5\%) \\
\hline Ivermectin & $\begin{array}{l}200 \mathrm{mcg} / \mathrm{kg} \text { of body weight } \\
\text { taken as one dose }\end{array}$ & Oral & $\begin{array}{l}\text { Nausea, vomiting, diarrhea (very } \\
\text { few reports on elevated liver } \\
\text { enzymes or jaundice: uncommon) }\end{array}$ \\
\hline Sarilumab & NA & Intravenous in COVID-19 trials & $\begin{array}{l}\text { Increased ALT; few cases of } \\
\text { gastrointestinal perforation }\end{array}$ \\
\hline Baricitinib & $2 \mathrm{mg}$ OD & Oral & $\begin{array}{l}\text { Bowel perforation, hepatitis } \mathrm{B} \\
\text { reactivation, nausea, vomiting }\end{array}$ \\
\hline
\end{tabular}

COVID-19 corona virus disease-19, GI gastrointestinal, $O D$ once daily, $B D$ twice daily, $I V$ intravenous, $N A$ not applicable, $H I V$ human immunodeficiency virus, $A L T$ alanine aminotransferase 


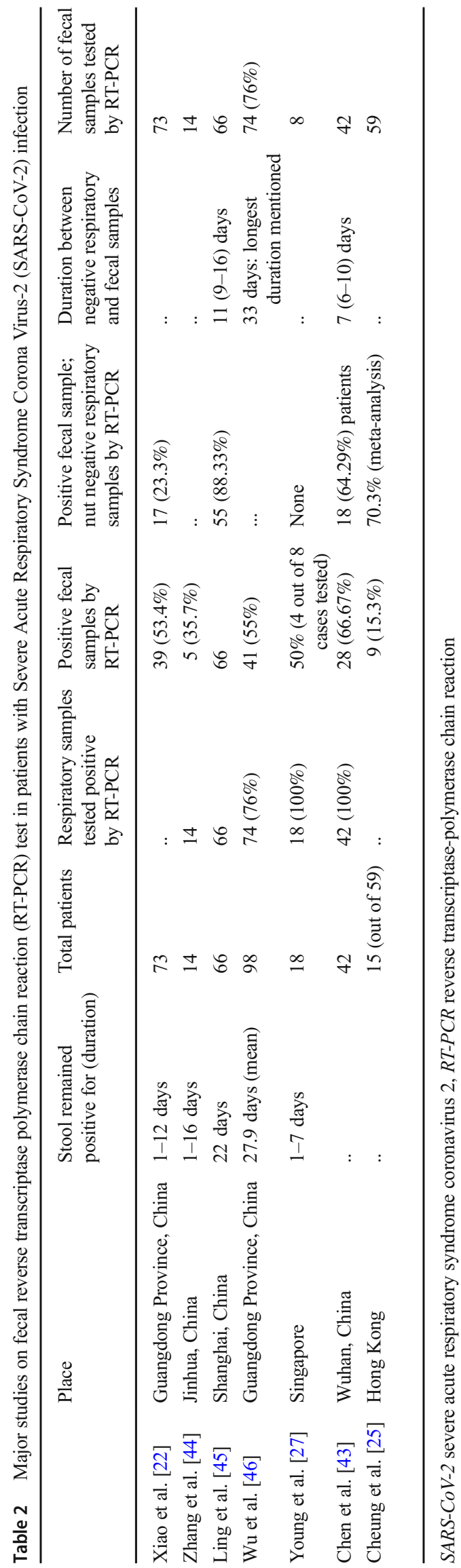

Fecal shedding: objective evidence of GI involvement

All the suspected cases of COVID-19 are tested by nucleic acid amplification tests (NAAT) on the samples from the upper/lower respiratory tract. These samples are monitored for clearance of the virus during the resolution of the disease. Feco-oral route of transmission has earlier been described in SARS-CoV and MERS-CoV during the course of the illness. A study by Corman et al. [42] verified MERS-CoV RNA in $14.6 \%$ of stool specimens. SARS-CoV-2, belonging to the same family, follows suit.

The first case reported from the USA tested positive for SARS-CoV-2 had fecal positivity on day 7 of illness [2]. Chen et al. [43] conclusively showed that $28(66.67 \%)$ of 42 laboratory-confirmed COVID-19 patients tested positive for SARS-CoV-2 RNA in stool specimens. The positivity rate is usually neither associated with the presence of GI symptoms nor the severity of illness, though Cheung et al. [25] did report high stool RNA in those presenting with diarrhea (38.5\% vs. $8.7 \%$ ) (Table 2).

The fecal test becomes positive around 2-5 days after oropharyngeal swab positivity, and the positivity lasts for $1-$ 16 days. It can stay positive for a period longer than the respiratory samples ( 28 days vs. 17 days), maximum reported up to 5 weeks $[44,46]$. In a recent meta-analysis, $48.1 \%$ had positive stool viral RNA during the illness [25]. Intriguingly $70.3 \%$ (range $23.3 \%$ to $88.3 \%$ ) of patients had persistent fecal positivity, for a mean period of 11 (9-16) days, even after the respiratory samples have become negative [22, 25, 45]. Additionally, only half of them had diarrhea [45]. Another systematic review showed that as high as $62.8 \%(125 / 199)$ of the positive fecal viral RNA cases had persistence of the virus in the stool after the oro-pharyngeal swab had turned negative [47].

Worldwide, the decision to discharge the patient from the hospital is based on negative RT-PCR test result from at least two sequential respiratory tract specimens collected at an interval of $\geq 24 \mathrm{~h}$ [24]. However, the longest fecal shedding (after negative respiratory viral RNA) is around 33 days, making discharging without fecal testing a tricky proposition [46]. Thus, fecal sampling can be used as an adjunct for initial diagnosis, in case of negative respiratory sample and high clinical suspicion. Moreover, it might be advisable to at least test for fecal/anal samples for RT-PCR at the time of discharge and adopt better control measures during the convalescent phase.

This provides hard evidence for the fact that the GI tract acts as a potent source of viral shedding. Its doubtful correlation with clinical symptomatology makes it difficult to ascertain the time when a case can be labelled non-infective during the convalescent phase. Moreover, it has been demonstrated that the virus is viable for $3 \mathrm{~h}$ in aerosol form and 2-3 days on plastic and stainless-steel surfaces [48]. Samples collected from the surface of toilet bowl, sink bowl, and door handle 
of the washroom used by a fecal positive patient were found to be positive for SARS-CoV-2 before disinfection, emphasizing the importance of hygiene maintenance [49]. Interestingly, in a proof of concept study, SARS-CoV-2 RNA was isolated from a waste-water catchment area in Australia, further highlighting the implication of this route of transmission [50]. Prolonged fecal shedding along with extended in vitro survival and toilet fume generation makes the virus a potent agent for efficient surface transmission using the feco-oral route.

Of late, CDC states that replication-competent virus could not be cultured from respiratory swab beyond 9 days of onset of illness and the infective virus could not be reliably cultured from the feces. Thus, the fecal route might contribute very little to the overall risk of transmission [51].

Recently, guidelines have been published to test stool donors for fecal microbiota transplantation (FMT) who have typical COVID-19 symptoms in the previous 30 days and those having travel history to COVID-19 prone regions or contact with COVID-19 suspects/proven cases in the preceding 30 days [52].

\section{COVID-19 concomitant with other GI conditions}

Besides the GI effects of SARS-CoV-2, the infection can itself possibly aggravate pre-existing GI diseases. Pre-existing conditions might flare up like inflammatory bowel disease (IBD) or the baseline immunosuppression in these sub-groups of individuals might lead them to have severe COVID-19.

\section{COVID-19 and IBD}

Although data is lacking, IBD patients are presumed to have increased susceptibility to COVID-19 . The high-risk population in IBD cohorts include elderly patients, smokers, those on prolonged high-dose steroids (>20 mg/day), pregnant women, children, those with underlying comorbidities, and those having active disease. IBD patients, however, do not seem to have an increased risk of acquiring SARS-CoV-2 infection [53]. Realworld data on the actual outcome of the effects of SARS-CoV2 infection in IBD patients are scanty [54]. An international registry (Surveillance Epidemiology of Coronavirus Under Research Exclusion [SECURE-IBD]) has been formulated to determine the outcome of these patients [55]. Of late, the International Organization of IBD (IOIBD) has opined that use of ustekinumab and vedolizumab does not increase the infection risk, but thiopurines, anti-tumor necrosis factor (antiTNF) agents, and Janus kinase- 2 inhibitors (JAK 2 inhibitors) have a debatable risk [56]. Suspension of regular outpatient services during this pandemic has reportedly resulted in an interruption in medications and sometimes disease exacerbation. Probably, "tele-medicine" as being advocated recently can help in unravelling this complex socio-medical issue. A detailed review of the interactions of COVID-19 and IBD will be dealt with in a separate article in this issue [57].

The various society guidelines (Asian-Pacific Association of Gastroenterology IBD group [58], European Society for Pediatric Gastroenterology Hepatology and Nutrition [59], European Crohn's and Colitis Organization [60], Bristish Society of Gastroenterology [61], Crohn's and Colitis Foundation [62], American Gastroenterological Association [63], World Endoscopy Organization [64]) have been enlisted in Supplementary Table 2 and a summary of the recommendations for IBD management during the COVID-19 pandemic have been outlined in Appendix Panel 2.

\section{Effects of COVID-19 on the pancreas}

In a study of 52 cases of SARS-CoV-2 pneumonia, $17 \%$ had a pancreatic injury (defined by elevated amylase $>90 \mathrm{U} / \mathrm{L}$ or lipase $>70 \mathrm{U} / \mathrm{L}$ ). Those with pancreatic injury had a higher incidence of anorexia and diarrhea and more severe illness on admission. Three possible explanations include ACE2 receptors on pancreatic islets causing acute diabetes, cytokine storm, and drug-induced pancreatic injury [65]. In a case series, 2 out of 3 family members were diagnosed to have severe acute pancreatitis related to COVID-19 [66].

\section{Nutrition therapy for COVID-19 patients}

The strategy for nutritional therapy to be adopted for COVID19 patients has been outlined in the joint guidance statements by the European Society for Clinical Nutrition and Metabolism (ESPEN) [67]. This has been summarized in (Appendix Panel 3).

\section{Endoscopic practices during COVID-19 pandemic: guidelines and summary of the recommendations for practicing gastroenterologists}

Last but not the least, from a gastroenterologist's perspective, the practice of endoscopy to be followed in the wake of the COVID-19 pandemic is of utmost importance. In one of the earliest reports from Wuhan, around 29\% positive cases (40 out of 138 cases) were healthcare workers [30], suggesting an increased risk of transmission, and hence greater importance of learning the art of donning and doffing the personal protective equipment (PPE). The possible routes of transmission during an endoscopic procedure can be person to person, droplet mode, aerosols generated in the positive pressure 
room, and contact with contaminated bodily fluids and fecal matter. The risk of transmission enhances manifold due to multitude of factors: (i) fomites transferred from the patient's respiratory secretions into the endoscopy room, more so when the viral load is high; (ii) endoscopic procedures are high aerosol-generating procedures, because of coughing and retching during upper GI endoscopy and passage of flatus during colonoscopy; (iii) suctioning and exchange of accessories during endoscopy pose a further risk by splashing and spreading of infective material; (iv) biopsy specimens too are infective as pointed out earlier. Thus, various societies (Asian-Pacific Society for Digestive Endoscopy [68], American Gastroenterological Association [69], European Society of Gastrointestinal Endosocpy [70], World Endoscopy Organization [71], American Society for Gastrointestinal Endoscopy [72], British Society of Gastroenterology [73], Indian Society of Gastroenterology/ Society of Gastrointestinal Endosocpy of India/Indian National Association for the Study of Liver joint guidance [74]) have come up with guidance statements to be strictly

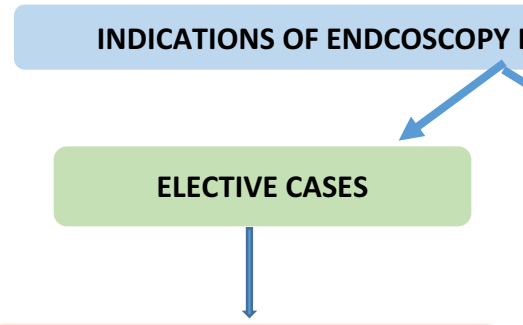

- POSTPONe AlL

- CALL THEM AFTER RESUMPTION OF THE ENDOSCOPY PRACTICES (starting the case load by $30 \%$ )

\section{EMERGENCY CASES}

The following cases are to be done:

GI bleed, Cholangitis/EHBO, Foreign body obstruction, perforation/leaks management, Stent placement in case of obstruction, Drainage of infected collections, RT/NJ/PEG placement for feeding, managing complications of cancer/its treatment

Training for PPE for all (endoscopist and staff) Donning and Doffing areas separate

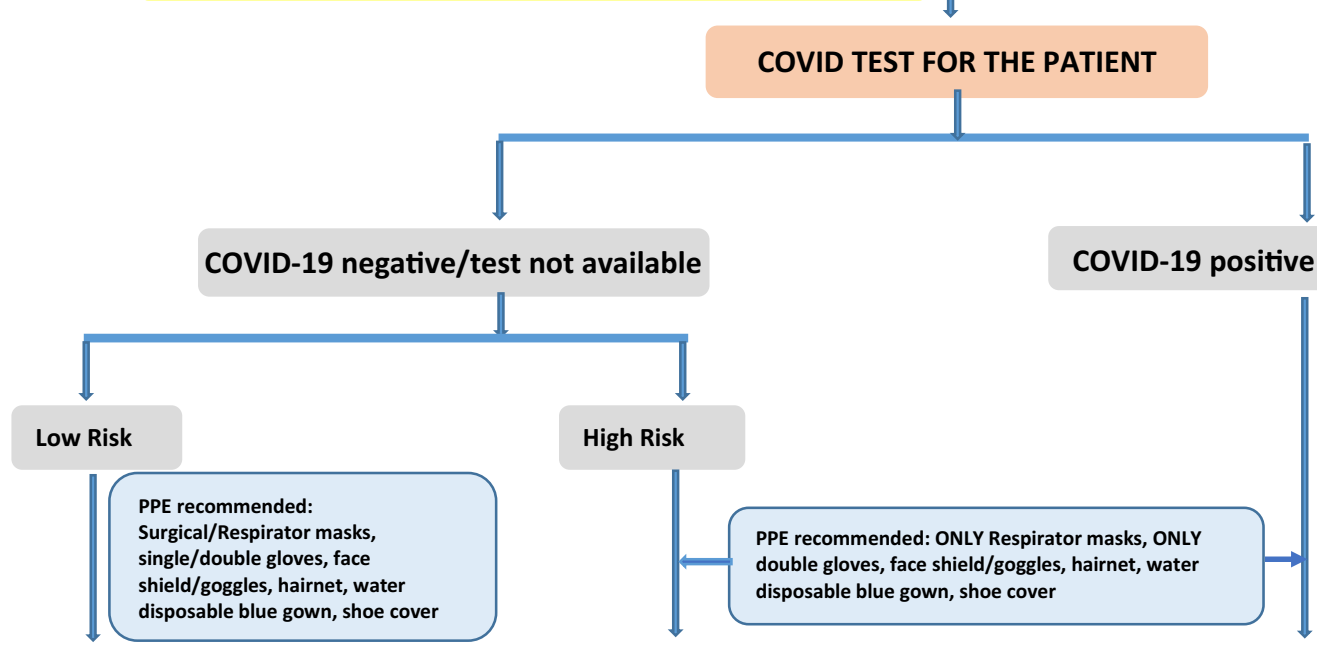

NEGATIVE PRESSURE ROOMS: 1 ENDOSCOPIST/2 NURSES

POST PROCEDURE

- Standard disinfection practices recommended by ASGE

- Proper hand hygiene

- Follow-up the patients and health care workers for new onset symptoms

Fig. 1 Flowchart summarizing recommendations for endoscopy during the COVID-19 pandemic. GI gastrointestinal, EHBO extrahepatic biliary obstruction, $R T$ Ryle's tube, $N J$ naso-jejunal tube, $P E G$ percutaneous endoscopic gastrostomy, FTOCC fever, travel, occupation, clustering, contact, COVID-19 corona virus disease-19, $P P E$ personal protective equipment, $A S G E$ American Society for Gastrointestinal Endoscopy 
followed by practicing gastroenterologists (Supplementary Table 3). Based on these statements, a flowchart has been proposed in Fig. 1, and recommendations have been summarized in Appendix Panel 4.

\section{Management of GI-related symptoms due to CoVID-19}

The management of GI symptoms necessitates the same steps to be followed like for any other disease. The presence of diarrhea could be due to the virus itself, drug-related, or dysbiosis in the GI tract. Proper hydration (especially the use of oral rehydration solution) to maintain electrolyte balance is essential. Sometimes, loperamide or other anti-diarrheal agents can be recommended to tide over the situation. Probiotics (to treat dysbiosis) and antispasmodics for treating abdominal pain can be added. Various digestive symptoms have diverse etiologies which should be looked into if symptomatic management does not tide over the situation.

For any new-onset GI symptoms such as diarrhea, patients should be evaluated for (i) risk of contact exposure, (ii) the detailed history of COVID-19-related symptoms, (iii) history for other GI symptoms, and (iv) in cases of high prevalence setting, monitoring of the cases for later development of respiratory symptoms. For patients undergoing drug therapy in hospitalized cases, evaluation for drug-related side effects is to be monitored [12].

\section{Prevention of feco-oral transmission}

GI involvement with fecal shedding provides hard evidence to this route being a potential health hazard. It is important to prevent it to curb its spread. All over the world, especially in developing countries, and more importantly as gastroenterologists, the need of the hour is to encompass the conventional practice of hand hygiene taught to us for ages. Everyone must avoid the conventional five " $F$ " factors responsible for fecooral transmission: fingers, flies, fluids, food, and fields. Community education programs, if possible by tele-communication, to raise awareness about safe food practices, hand hygiene, and forbidding open defecation are cornerstones in preventing the spread of the disease and need to be meticulously implemented.

\section{Hiatus in the available literature}

The data available until now is not only inadequate but also rigged with bias. Duration of GI symptoms, isolated or along with other manifestations, and follow-up have not been systematically evaluated. A significant publication bias was noted for GI symptoms [31]. Whether GI symptoms are due to virus replication or because of mucosal immunity interactions is not clear. For cases presenting with GI symptoms initially, whether the GI tract is the first site of infection is not known. The true impact of this infection on pre-existing diseases such as IBD is still in its nascent stage. While early data pointed towards no increased risk, more data over time will spell out the real scenario. The impact of fecal shedding on the transmission dynamics is unclear. Whether the virus isolated in the fecal samples can be adequately cultured is not known, and if yes, whether that factor is sufficient enough to render the stool infective enough for transmission or not needs to be established. Moreover, the implication of virus isolation in sewage water on community transmission has to be explored. These and a host of other questions have to be answered before we can confidently embark on future management recommendations. Finally, peer review in the publication process is essential in maintaining the quality of publications and has to be ensured even for COVID-19 data as well.

\section{Conclusion}

GI manifestations are not uncommon in patients with COVID19 , and more intriguing is the presence of a sub-group of these cases presenting only with GI symptoms. Fecal shedding of the virus objectively establishes GI tract involvement but also underscores its implications on formulating preventive strategies. Future studies and data are needed to define the role of fecal testing for initial diagnosis or during discharge. The data and hence the recommendations for optimum management of difficult situations such as IBD with COVID-19 are still evolving. For the practicing gastroenterologists, not only patient management but also personal safety is of prime importance. Resorting to "tele-medicine" facilities for patient management, restricting unnecessary procedures, and following strict protective strategies are key to help sail through these difficult times. During this era of COVID-19 pandemic, as more and more data keep pouring in every day, we need to unlearn many old habits and learn a few new ones to protect ourselves and our patients and tread the path more carefully.

Author contributions All authors contributed to the study conception and design. Material preparation, data collection, and analysis were performed by Jahnvi Dhar and Jayanta Samanta. The first draft of the manuscript was written by Jahnvi Dhar and Jayanta Samanta, and all authors commented on previous versions of the manuscript. All authors read and approved the final manuscript. Jahnvi Dhar and Jayanta Samanta contributed equally to the work.

\section{Compliance with ethical standards}

Conflict of interests JD, JS, and RK declare that they have no conflict of interest. 
Disclaimer The authors are solely responsible for the data and the contents of the paper. In no way, the Honorary Editor-in-Chief, Editorial Board Members, or the printer/publishers are responsible for the results/ findings and content of this article.

\section{Appendix}

Panel 1 Overall reported incidence rates of gastrointestinal manifestations

- Cumulative digestive symptoms: $2 \%-57 \%$

- Diarrhea: $1 \%-36.6 \%$

- Nausea: $1 \%-22 \%$

- Vomiting: $3.6 \%-15.9 \%$

- Abdominal pain: $1.3 \%-9 \%$

- Loss of appetite: $1 \%-79 \%$

- Gastrointestinal bleeding: 4\%-13.7\%

- Loss of taste (gustatory dysfunction): $5.6 \%-92.6 \%$

- Loss of smell (olfactory dysfunction): $5.1 \%-98.3 \%$

- Stool ribonucleic acid positivity: $36 \%-53 \%$

Panel 2 Key recommendations for managing inflammatory bowel disease patients during the COVID-19 pandemic

- High-risk population in the IBD cohort

- Elderly $>65$ years

- Those with underlying comorbidities: hypertension, diabetes mellitus, chronic liver diseases

- Pregnancy with IBD

- Those not in clinical and/or endoscopic remission: especially with moderate/active disease

- Those on immunosuppressive medications: especially on prolonged, high-dose steroids $>20 \mathrm{mg} /$ day, followed by thiopurines, biological agents, JAK inhibitors

- Summary of the recommendations by various society guidelines regarding use of medications in IBD patients

- Protective measures to be followed: social distancing, facial masks, hand hygiene

- Emphasis on tele-medicine services to overcome decreased hospital visits

- Can safely continue 5-ASAs (amino salicylates) in both presumed and active COVID-19

- To continue steroids but subsequently taper to the lowest effective dose during active infection; budesonide can be an alternative

- To continue with thiopurines, biological agents, JAK inhibitors, but to stop all during active COVID-19

- For the use of biological agents: prefer monotherapy; and no switching of class; can receive infusions in a facility having SARS-CoV-2 testing protocol; If infliximab infusion not possible, consider switching to adalimumab (subcutaneous injection) at home (only during the period of the pandemic)
Panel 2 (continued)

- Vedolizumab and ustekinumab do not increase the risk of COVID-19: to be continued safely

- Exclusive enteral nutrition to be used if biological is not available

- Non-invasive monitoring: CRP, fecal calprotectin, procalcitonin recommended by few societies

- If a case is SARS-CoV-2 positive but asymptomatic: steroids to be reduced to $<20 \mathrm{mg} /$ day, or switch to budesonide, stop thiopurines, methotrexate, tofacitinib, delay the dosing of monoclonal for 2 weeks and monitor for COVID-19

- If symptomatic COVID-19 present: only continue 5 ASAs and local therapy, oral budesonide recommended by some, rest all medications to stop. Restart all the above after 2 weeks of resolution of symptoms

- For clinical trials, new enrolment should be postponed. For existing ones, can continue

- In children: continue all the medications in the usual dose (no dose reduction even if SARS-CoV-2 positive)

- Endoscopy in IBD patients during COVID-19 pandemic

- Defer all elective cases

- Emergency situations include newly diagnosed moderate/active IBD, acute flare of IBD, inflammatory intestinal obstruction necessitating endoscopic dilatation, to rule out CMV (Cytomegalovirus) colitis, managing cholangitis (especially dominant stricture associated) in primary sclerosing cholangitis with IBD

- Always triage with FTOCC protocol: fever, travel, occupation, contact, clustering (especially in the last 14 days)

- Always test for COVID-19: naso/oro-pharyngeal swab with RT-PCR and CECT chest if needed

- In newly diagnosed cases and acute flare of IBD:

- Rule out infectious causes (fecal calprotectin/CRP levels)

- Perform stool CDTA (Clostridium difficile), CMV DNA, stool cultures

- In moderate/severe signs of infection: perform sigmoidoscopy/colonoscopy with biopsies

- For mild disease, 5-ASA and/or budesonide are reasonable

- For moderate/severe disease, requiring steroid treatment, strict social distancing, and precautions to be adopted. Upfront biologicals (subcutaneous) may be considered

- In cases of IBD with intestinal obstruction:

- Perform abdominal CT/MRI in all

- If inflammatory stenosis: perform sigmoidoscopy/colonoscopy with biopsies with endoscopic stricture dilatation

- If fibrotic stenosis: refer to surgery

IBD inflammatory bowel disease, COVID-19 corona virus disease-19, $J A K$ Janus kinase, $S A R S-C o V-2$ severe acute respiratory syndrome coronavirus 2, $A S A$ amino salicylate, $C R P$ C-reactive protein, $C M V$ cytomegalovirus, $R T-P C R$ reverse transcriptase-polymerase chain reaction, $C E C T$ contrast-enhanced computed tomography, CDTA Clostridium difficile toxin assay, DNA deoxyribonucleic acid, MRI magnetic resonance imaging 
Panel 3 Key recommendations for nutrition therapy in COVID-19 patients

- Patients at high risk for poor outcome such as elderly and those with multiple comorbidities should be evaluated for malnutrition

- Those with malnutrition should have optimized nutritional therapy by diet counselling using weight-based formulae:

a. $27 \mathrm{kcal} / \mathrm{kg} /$ day for age $>65$ years with multiple comorbidities

b. $30 \mathrm{kcal} / \mathrm{kg} /$ day for severely malnourished with multiple comorbidities

c. Protein at the rate of $1 \mathrm{~g} / \mathrm{kg}$ body weight for older individuals. For multiple comorbidities, may consider $\geq 1 \mathrm{~g} / \mathrm{kg}$ of protein

- Adequate supplementation with vitamins and minerals in cases of malnutrition

- Regular physical activity for those in quarantine

- Oral nutritional supplements may be advocated in situation where diet counselling and food fortification are inadequate

- For intensive care unit (ICU) admitted patients:

a. Enteral nutrition (EN) preferred over parenteral nutrition (PN) (when gastrointestinal (GI) symptoms absent): placement of 10-12 F nasogastric tube. Consider post pyloric feeding if the above fails

b. PN preferred over EN when GI symptoms present and transitioning to EN when they subside.

c. Initiation of early EN within 24-36 h of admission to the ICU or within $12 \mathrm{~h}$ of intubation; continuous EN preferred over bolus feeding

d. Early PN in high-risk cases (shock, bowel ischemia, high positive pressure support is required); multi-chamber bags to be used to minimize exposure while handling

e. Confirmatory abdominal X-rays should be clustered with chest X-ray timings

f. To start with hypocaloric feeding, then increasing within 1 week to goal of $15-20 \mathrm{kcal} / \mathrm{kg}$ actual body weight $(\mathrm{ABW}) /$ day and protein of $1.2-2.0 \mathrm{~g} / \mathrm{kg} \mathrm{ABW} /$ day

g. Monitoring of serum triglyceride levels in those receiving propofol and/or intravenous lipid emulsions early in their course (as COVID-19 leads to secondary hemophagocytosis in some reported cases)

h. Even in prone position: EN to be considered over PN but with a reverse trendelenburg position to avoid gastric aspiration
Panel 4 Key recommendations for performing endoscopic procedures during the COVID-19 pandemic

\section{- Pre-procedure}

- Triage of indications on the basis of level of urgency

- Procedures not time-sensitive should be postponed

- Regular tele-monitoring of postponed patients to ensure that the condition does not turn urgent

- Risk stratification of cases on the basis of low, intermediate, and high risk for COVID-19

- N95 masks recommended for all GI endoscopy procedures

- Proper separate donning and doffing area: adequate training of HCWs

- All patients should wear surgical masks

- Adequate informed consent

- In-procedure Room

- Minimize the number of personnel: only 1 endoscopist and 2 assistants adequate

- Avoid personnel switching during procedures

- Proper hand hygiene to be followed

- Standard PPE for negative cases. Enhanced PPE for suspected/positive cases

- Use of double gloves preferable

- Goggles/face shield to be used

- Use of washable work boots to be used during the endoscopy session

- Negative pressure room/ HEPA filter/ use of exhaust fans

- During procedure

- Avoid aggressive suctioning and multiple catheter exchanges

- Minimum positive insufflation during endoscopy

- While using the accessory channel, the handle of the scope should be directed down and towards the left to minimize exposures

- All specimen, including biopsies, to be handled with extra precautions

- Precaution to be followed during colonoscopy as well

- Use of gauze piece to cover instrument channel and mouth of the scope after removal

- Endoscopist should alert the team during scope withdrawal

- Post-procedure

- Adequate disinfection with standard agents

- Disinfection of non-critical surfaces such as bedside tables, bed rails, computers, and phones to be done after each procedure

- Disposable devices not to be reused

- A gap of at least 30 min between two procedures

- Follow-up of negative patients and health care workers for any new-onset symptoms

COVID-19 corona virus disease-19, GI gastrointestinal, $H C W s$ healthcare workers, $P P E$ personal protective equipment, HEPA high-efficiency particulate air 


\section{References}

1. WHO. Coronavirus disease 2019 (COVID-19) situation report 120. 2020. https://www.who.int/docs/default-source/coronaviruse/ situation-reports/20200519-covid-19-sitrep-120.pdf?sfvrsn= 515cabfb_2. Accessed 19 May 2020.

2. Holshue ML, DeBolt C, Lindquist S, et al. First case of 2019 novel coronavirus in the United States. N Engl J Med. 2020;382:929-36.

3. Lu R, Zhao X, Li J, et al. Genomic characterisation and epidemiology of 2019 novel coronavirus: implications for virus origins and receptor binding. Lancet. 2020;395:565-74.

4. Huang C, Wang Y, Li X, et al. Clinical features of patients infected with 2019 novel coronavirus in Wuhan, China. Lancet. 2020;395: 497-506.

5. Epidemiology Working Group for NCIP Epidemic Response. Chinese Center for Disease Control and Prevention. Zhonghua Liu Xing Bing Xue Za Zhi. 2020;41:145-51.

6. $\mathrm{Hu} \mathrm{Y}$, Sun J, Dai Z, et al. Prevalence and severity of corona virus disease 2019 (COVID-19): A systematic review and meta-analysis. J Clin Virol. 2020;127:104371.

7. Hui DS, Azhar EI, Kim YJ, et al. Middle East respiratory syndrome coronavirus: risk factors and determinants of primary, household, and nosocomial transmission. Lancet Infect Dis. 2018;18:e217e27.

8. Stadler K, Masignani V, Eickmann M, et al. SARS -beginning to understand a new virus. Nat Rev Microbiol. 2003;1:209-18.

9. Zhou P, Yang XL, Wang XG, et al. A pneumonia outbreak associated with a new coronavirus of probable bat origin. Nature. 2020;579:270-3.

10. Chan JF, Yuan S, Kok KH, et al. A familial cluster of pneumonia associated with the 2019 novel coronavirus indicating person-toperson transmission: a study of a family cluster. Lancet. 2020;395: 514-23.

11. Guan WJ, Ni ZY, Hu Y, et al. Clinical characteristics of coronavirus disease 2019 in China. N Engl J Med. 2020;382:1708-20.

12. Sultan S, Altayar O, Siddique SM, et al. AGA institute rapid review of the GI and liver manifestations of COVID-19, meta-analysis of international data, and recommendations for the consultative management of patients with COVID-19. Gastroenterology. 2020;159: 320-34.e27.

13. Yan R, Zhang Y, Li Y, et al. Structural basis for the recognition of SARS-CoV-2 by full-length human ACE2. Science. 2020;367: 1444-8.

14. Wan Y, Shang J, Graham R, et al. Receptor recognition by the novel coronavirus from Wuhan: an analysis based on decade-long structural studies of SARS coronavirus. J Virol. 2020;94:e00127-0.

15. Zhang H, Kang Z, Gong H, et al. Digestive system is a potential route of COVID-19: an analysis of single-cell coexpression pattern of key proteins in viral entry process. Gut. 2020;69:1010-8.

16. Liang W, Feng Z, Rao S, et al. Diarrhoea may be underestimated: a missing link in 2019 novel coronavirus. Gut. 2020;69:1141-3.

17. Hashimoto T, Perlot T, Rehman A, et al. ACE2 links amino acid malnutrition to microbial ecology and intestinal inflammation. Nature. 2012;487:477-81.

18. Lin L, Jiang X, Zhang Z, et al. Gastrointestinal symptoms of 95 cases with SARS-CoV-2 infection. Gut. 2020;69:997-1001.

19. Holmes KV. Enteric infections with coronaviruses and toroviruses. In Novartis Foundation Symposium 2001 Jun 29. Chichester: John Wiley; 1999.

20. Liu Q, Wang RS, Qu GQ, et al. Gross examination report of a COVID-19 death autopsy. Fa Yi Xue Za Zhi. 2020;36:21-3.

21. Budden KF, Gellatly SL, Wood DL, et al. Emerging pathogenic links between microbiota and the gut-lung axis. Nat Rev Microbiol. 2017;15:55-63.
22. Xiao F, Tang M, Zheng X, et al. Evidence for gastrointestinal infection of SARS-CoV-2. Gastroenterology. 2020;158:1831-3.e3.

23. Xie C, Jiang L, Huang G, et al. Comparison of different samples for 2019 novel coronavirus detection by nucleic acid amplification tests. Int J Infect Dis. 2020;93:264-7.

24. Tian Y, Rong L, Nian W, He Y. Review article: gastrointestinal features in COVID-19 and the possibility of faecal transmission. Aliment Pharmacol Ther. 2020;51:843-51.

25. Cheung KS, Hung IF, Chan PP, et al. Gastrointestinal manifestations of SARS-CoV-2 infection and virus load in fecal samples from the Hong Kong Cohort: Systematic review and meta-analysis. Gastroenterology. 2020;159:81-95.

26. Song Y, Liu P, Shi XL, et al. SARS-CoV-2 induced diarrhoea as onset symptom in patient with COVID-19. Gut. 2020;69:1143-4.

27. Young BE, Ong SWX, Kalimuddin S, et al. Epidemiologic features and clinical course of patients infected with SARS-CoV-2 in Singapore. JAMA. 2020;323:1488-94.

28. Hosoda T, Sakamoto M, Shimizu H, Okabe N. SARS-CoV-2 enterocolitis with persisting to excrete the virus for approximately two weeks after recovering from diarrhea: a case report. Infect Control Hosp Epidemiol. 2020;41:753-4.

29. Fang Dan M, Guan J, Wang M. Manifestations of digestive system in hospitalized patients with novel coronavirus pneumonia in Wuhan, China: a single-center, descriptive study. Chin J Dig. 2020; 40(3)

30. Wang D, Hu B, Hu C, et al. Clinical characteristics of 138 hospitalized patients with 2019 novel coronavirus-infected pneumonia in Wuhan, China. JAMA. 2020;323:1061-9.

31. Mao R, Qiu Y, He JS, et al. Manifestations and prognosis of gastrointestinal and liver involvement in patients with COVID-19: a systematic review and meta-analysis. Lancet Gastroenterol Hepatol. 2020;5:667-78.

32. Jin X, Lian JS, Hu JH, et al. Epidemiological, clinical and virological characteristics of 74 cases of coronavirus-infected disease 2019 (COVID-19) with gastrointestinal symptoms. Gut. 2020;69:10029.

33. Henry BM, de Oliveira MHS, Benoit J, Lippi G. Gastrointestinal symptoms associated with severity of coronavirus disease 2019 (COVID-19): a pooled analysis. Intern Emerg Med. 2020:1-3.

34. An P, Chen H, Jiang X, et al. Clinical features of 2019 novel coronavirus pneumonia presented gastrointestinal symptoms but without fever onset. 2020. https://doi.org/10.2139/ssrn.3532530.

35. Pan L, Mu M, Yang P, et al. Clinical characteristics of COVID-19 patients with digestive symptoms in Hubei, China: a descriptive, cross-sectional, Multicenter Study. Am J Gastroenterol. 2020;115: 766-73.

36. Luo S, Zhang X, Xu H. Don't overlook digestive symptoms in patients with 2019 novel coronavirus disease (COVID-19). Clin Gastroenterol Hepatol. 2020;18:1636-7.

37. Liu W, Zhang Q, Chen J, et al. Detection of Covid-19 in children in early January 2020 in Wuhan, China. N Engl J Med. 2020;382: 1370-1.

38. Mao L, Jin H, Wang M, et al. Neurologic manifestations of hospitalized patients with coronavirus disease 2019 in Wuhan, China. JAMA Neurol. 2020;77:1-9.

39. Tong JY, Wong A, Zhu D, et al. The prevalence of olfactory and gustatory dysfunction in COVID-19 patients: a systematic review and meta-analysis. Otolaryngol Head Neck Surg. 2020;163:3-11.

40. CDC. Symptoms of coronavirus. 2020. https://www.cdc.gov/ coronavirus/2019-ncov/symptoms-testing/symptoms.html. Accessed 13 May 2020.

41. Sanders JM, Monogue ML, Jodlowski TZ, Cutrell JB. Pharmacologic treatments for coronavirus disease 2019 (COVID19): a review. JAMA. 2020. https://doi.org/10.1001/jama.2020. 6019. 
42. Corman VM, Albarrak AM, Omrani AS, et al. Viral shedding and antibody response in 37 patients with Middle East respiratory syndrome coronavirus infection. Clin Infect Dis. 2016;62:477-83.

43. Chen Y, Chen L, Deng Q, et al. The presence of SARS-CoV-2 RNA in the feces of COVID-19 patients. J Med Virol. 2020;92: 833-40.

44. Zhang J, Wang S, Xue Y. Fecal specimen diagnosis 2019 novel coronavirus-infected pneumonia. J Med Virol. 2020;92:680-2.

45. Ling $\mathrm{Y}, \mathrm{Xu} \mathrm{SB}$, Lin YX, et al. Persistence and clearance of viral RNA in 2019 novel coronavirus disease rehabilitation patients. Chin Med J (Engl). 2020;133:1039-43.

46. Wu Y, Guo C, Tang L, et al. Prolonged presence of SARS-CoV-2 viral RNA in faecal samples. Lancet Gastroenterol Hepatol. 2020;5: 434-5.

47. Gupta S, Parker J, Smits S, et al. Persistent viral shedding of SARSCoV-2 in faeces - a rapid review. Color Dis. 2020;22:611-20.

48. van Doremalen N, Bushmaker T, Morris DH, et al. Aerosol and surface stability of SARS-CoV-2 as compared with SARS-CoV-1. N Engl J Med. 2020;382:1564-7.

49. Ong SWX, Tan YK, Chia PY, et al. Air, surface environmental, and personal protective equipment contamination by severe acute respiratory syndrome coronavirus 2 (SARS-CoV-2) from a symptomatic patient. JAMA. 2020;323:1610-2.

50. Ahmed W, Angel N, Edson J, et al. First confirmed detection of SARS-CoV-2 in untreated wastewater in Australia: a proof of concept for the wastewater surveillance of COVID-19 in the community. Sci Total Environ. 2020;728:138764.

51. CDC. Symptom-based strategy to discontinue isolation for persons with COVID-19. 2020. https://www.cdc.gov/coronavirus/2019$\mathrm{ncov} / \mathrm{community} / \mathrm{strategy-discontinueisolation.html?}$ deliveryName=USCDC 2067-DM27395. Accessed 3 May 2020.

52. Ianiro G, Mullish BH, Kelly CR, et al. Screening of faecal microbiota transplant donors during the COVID-19 outbreak: suggestions for urgent updates from an international expert panel. Lancet Gastroenterol Hepatol. 2020;5:430-2.

53. Norsa L, Indriolo A, Sansotta N, Cosimo P, Greco S, D'Antiga L. Uneventful course in patients with inflammatory bowel disease during the severe acute respiratory syndrome coronavirus 2 outbreak in northern Italy. Gastroenterology. 2020;S00165085(20)30445-5.

54. Bezzio C, Saibeni S, Variola A, et al. Outcomes of COVID-19 in 79 patients with IBD in Italy: an IG-IBD study. Gut. 2020;69:1213-7.

55. Brenner EJ UR, Colombel JF, Kappelman MD. SECURE-IBD Database Public Data Update. 2020. https://covidibd.org/currentdata/. Accessed 18 May 2020.

56. IOIBD. IOIBD update on COVID19 for patients with Crohn's disease and ulcerative colitis. 2020. https://www.ioibd.org/ioibdupdate-on-covid19-for-patients-with-crohns-disease-andulcerative-colitis/. Accessed 13 April 2020.

57. Baryah ANS, Midha V, Mahajan R, Sood A. Impact of corona virus disease - 19 (COVID-19) pandemic on gastrointestinal disorders. Indian J Gastroenterol. 2020; 39. https://doi.org/10.1007/ s12664-020-01071-6.

58. Ling KL, Hilmi I, Raja Ali RA, et al. Asian Pacific Association of Gastroenterology (APAGE) Inflammatory Bowel Disease (IBD) Working Party guidelines on IBD management during the COVID-19 pandemic. JGH Open. 2020;4:320-3.

59. Turner D, Huang Y, Martín-de-Carpi J, et al. COVID-19 and paediatric inflammatory bowel diseases: global experience and provisional guidance (March 2020) from the PAEDIATRIC IBD Porto
Group of European Society of Paediatric Gastroenterology, Hepatology, and Nutrition. J Pediatr Gastroenterol Nutr. 2020;70: 727-33.

60. ECCO. 1st Interview COVID-19 ECCO Taskforce. 2020. https:// www.ecco-ibd.eu/images/6 Publication/6 8 Surveys/1st interview_COVID-19\%20ECCOTaskforce_published.pdf. Accessed 13 April 2020.

61. Kennedy NA, Jones GR, Lamb CA, et al. British Society of Gastroenterology guidance for management of inflammatory bowel disease during the COVID-19 pandemic. Gut. 2020;69:984-90.

62. Foundation CsaC. Resources for IBD healthcare professionals: 2019 novel coronavirus (COVID-19). 2020. https://www. crohnscolitisfoundation.org/coronavirus/professional-resources. Accessed 6 April 2020.

63. Rubin DT, Feuerstein JD, Wang AY, Cohen RD. AGA clinical practice update on management of inflammatory bowel disease during the COVID-19 pandemic: expert commentary. Gastroenterology. 2020;159:350-7.

64. Neumann H, Emura F, Bokemeyer B, et al. Practical advice for management of IBD patients during the COVID-19 pandemic: a world endoscopy organization statement. Dig Endosc. 2020;32: 658-62.

65. Wang F, Wang H, Fan J, Zhang Y, Wang H, Zhao Q. Pancreatic injury patterns in patients with COVID-19 pneumonia. Gastroenterology. 2020;159:367-70.

66. Hadi A, Werge MP, Kristiansen KT, et al. Coronavirus disease-19 (COVID-19) associated with severe acute pancreatitis: case report on three family members. Pancreatology. 2020;20:665-7.

67. Barazzoni R, Bischoff SC, Breda J, et al. ESPEN expert statements and practical guidance for nutritional management of individuals with SARS-CoV-2 infection. Clin Nutr. 2020;39:1631-8.

68. Chiu PWY, Ng SC, Inoue $\mathrm{H}$, et al. Practice of endoscopy during COVID-19 pandemic: position statements of the Asian Pacific Society for Digestive Endoscopy (APSDE-COVID statements). Gut. 2020;69:991-6.

69. Sultan S, Lim JK, Altayar O, et al. AGA institute rapid recommendations for gastrointestinal procedures during the COVID-19 pandemic. Gastroenterology. 2020;S0016-5085(20)30458-3.

70. Gralnek IM, Hassan C, Beilenhoff U, et al. ESGE and ESGENA position statement on gastrointestinal endoscopy and the COVID19 pandemic. Endoscopy. 2020;52:483-90.

71. WEO. WEO recommendations on digestive endoscopy and the COVID-19 pandemic. 2020. http://www.worldendo.org/wpcontent/uploads/2020/04/200409_WEO-Advice-to-EndoscopistsCOVID-19-Update-April-9-2020.pdf. Accessed 9 April 2020.

72. Repici A, Maselli R, Colombo M, et al. Coronavirus (COVID-19) outbreak: what the department of endoscopy should know. Gastrointest Endosc. 2020;92:192-7.

73. Guidelines BS. Endoscopy activity and COVID-19: BSG and JAG guidance. 2020. https://www.bsg.org.uk/covid-19-advice/ endoscopy-activity-and-covid-19-bsg-and-jag-guidance/. Accessed 3 April 2020

74. Philip M, Lakhtakia S, Aggarwal R, et al. Joint guidance from SGEI, ISG and INASL for gastroenterologists and gastrointestinal endoscopists on the prevention, care and management of patients with COVID-19. J Clin Exp Hepatol. 2020;10:266-70.

Publisher's note Springer Nature remains neutral with regard to jurisdictional claims in published maps and institutional affiliations. 